\title{
Immediate Postpartum IUD Training Within a Regional Network of Family Medicine Residencies
}

Ying Zhang, MD, MPH | Sonali Sheth, MD | Amanda K.H. Weidner, MPH | Patricia Egwuatu, DO | Lauren Webb, DO | Grace Shih, MD, MPH

PRiMER. 2021;5:24.

Published: 7/1/2021 | DOI: 10.22454/PRiMER.2021.421778

\section{Abstract}

Background and Objective: Immediate postpartum placement of intrauterine devices (PPIUD) offers important benefits to patients. Little is known about PPIUD training or knowledge within family medicine residency programs. We evaluated PPIUD experience and prior training among family medicine residents and faculty.

Methods: We conducted a cross-sectional survey of residents and faculty in 24 regional family medicine residency programs in 2018. Survey questions focused on reception of PPIUD training and experience with PPIUD counseling and placement.

Results: The final survey sample included 203 residents and 100 faculty with an overall response rate of $39 \%$. About $26 \%(n=79)$ of all participants reported receiving prior training for counseling and placement of PPIUDs, while $16 \%$ ( $n=48$ ) of participants had ever placed a PPIUD. Twenty-six percent $(n=78)$ of participants reported that their residency programs offered PPIUD training. Residents and faculty who reported past PPIUD training and/or placement experience were more likely to have ever counseled patients about PPIUD $(P<.001)$ and report that their primary training hospital offered PPIUD to patients $(P<.001)$ and their residency programs offered PPIUD training $(P<.001)$.

Conclusions: Few programs offer routine PPIUD training opportunities for family medicine residents and faculty, which may contribute to limited availability of PPIUD to patients. There is a need to improve PPIUD training and placement opportunities for both family medicine residents and faculty.

\section{Introduction}

Immediate postpartum, or postplacental, placement of intrauterine devices (PPIUD) provides benefits to patients by minimizing delays in desired care and necessary future clinic visits, and is cost-effective to health care systems when factoring in prevention of undesired future pregnancies. ${ }^{1-4}$ Despite the evidence for the safety, efficacy, and cost effectiveness of PPIUD, multiple barriers, including lack of provider knowledge and training, limit access to PPIUDs. ${ }^{5-10}$

Little is known about training for PPIUD counseling and placement in family medicine residency education. Our study aimed to assess training and experiences with PPIUD counseling and placement among both residents 
and faculty in family medicine residency programs, and to explore individual and program-specific factors that impact this training for each group.

\section{Methods}

In January 2018 through April 2018, we conducted an electronic cross-sectional survey of residents and faculty in 24 civilian allopathic family medicine residency programs $(\mathrm{N}=811 ; 252$ faculty and 559 residents) across the Washington, Wyoming, Alaska, Montana, Idaho (WWAMI) region, using contact information from a collaborative network of these programs, the University of Washington (UW) Family Medicine Residency Network (FMRN). Participants were asked to answer a series of questions regarding training and experience with PPIUD counseling and placement; we collected, stored, and managed data via REDCap (Research Electronic Data Capture). ${ }^{11}$

We collected demographic data including participants' gender, age, years of postresidency practice (for faculty) or year in residency (for residents), and current obstetrical (OB) practice (for faculty) and future OB practice intentions (for residents). In addition, participants self-reported whether their primary training hospitals offered PPIUD to patients. The FMRN provided information regarding whether residency programs offered $O B$ fellowship training. Outcomes of interest included whether participants ever counseled patients about PPIUD, received training in PPIUD placement, had ever placed a PPIUD and the total number of PPIUDs placed.

We used descriptive statistics to evaluate sample characteristics. We used the $c^{2}$ test to evaluate factors associated with receipt of PPIUD training and experience with PPIUD placement as well as to assess differences in comfort with PPIUD knowledge and placement among faculty and residents who had or had not ever received training. We analyzed using SPSS software version 19.0.0 (IBM Corp, Armonk NY). The UW Institutional Review Board reviewed this study and deemed it exempt (category 2 for educational research).

\section{Results}

The overall response rate was 39\% (316/811). After excluding those who did not respond to any questions $(n=2)$ and faculty who did not supervise any obsterical care $(n=11)$, the final sample included 303 respondents: 203 residents and 100 faculty. We received responses from residents and faculty from each residency program surveyed. The response rate by program ranged from $14 \%$ to $57 \%$ with a median and mean of $37 \%$ for all programs. Participant and program characteristics are described in Table 1 . The majority of participants (62\%) were affiliated with Washington-based residency programs, which was reflective of the proportion of overall surveys sent to Washington-based programs (60\%). Notably, $20 \%$ of all participants were from programs with OB fellowship training available. Additionally, the majority (57\%) of all participants responded that their primary training hospitals did not provide PPIUD to patients.

About $36 \%$ ( $n=73$ ) of residents and $43 \%(n=43)$ of faculty reported ever having counseled a patient about PPIUD. More faculty than residents reported ever having received training for PPIUD placement (36\% vs $21 \%$ ) and ever having placed a PPIUD ( $27 \%$ vs $10 \%$; Table 2$)$. The majority of resident $(n=158,78 \%)$ and faculty $(n=60$, $60 \%$ ) participants were either interested or very interested in receiving training in PPIUD counseling and placement regardless of prior training.

Individual- and program-specific characteristics for residents and faculty with receipt of PPIUD training or PPIUD placement experience included the primary training hospital offering PPIUD to patients, the residency program offering PPIUD training, and having ever counseled patients about PPIUD (all $P<.001$; Tables 3 and 4).

Experience with placing PPIUDs was significantly associated with having received PPIUD training $(P<.001)$. No significant associations were found between age, gender, years in practice/residency year, and inpatient or 


\section{Conclusions}

In our study, the first to include family medicine residents in assessing training and experience with PPIUD counseling and placement, the majority of respondents reported no previous training nor hands-on experience with counseling patients for and placing PPIUDs. A higher percentage of faculty respondents compared with resident respondents reported prior PPIUD training and placement experience, which may be due to the longer time faculty respondents have been in clinical practice. A previous survey of attending-level educators (eg, obstetricians, family physicians, and midwives) revealed that the most common reason for never placing a PPIUD was inadequate training. ${ }^{6}$ Our results for faculty respondents are similar to other studies of attending level family physicians and midwives showing an overall low level of PPIUD training and placement experience. 6,9,11 These findings reveal an important opportunity to improve contraceptive education and training among family medicine residents and faculty and to expand postpartum contraceptive options among patients.

Survey participants who received prior PPIUD training were more likely to have experience with counseling patients for and placing PPIUDs. Additionally, residency programs offering PPIUD training and participants' training hospitals offering PPIUD placement to patients were factors significantly associated with both residents and faculty having received training and placing PPIUDs. Up to $40 \%$ of women who desire long-acting reversible contraception in the postpartum period do not receive it, commonly because of early repeat pregnancy or missing postpartum follow-up visits. ${ }^{12}$ Thus, integrating PPIUD training into family medicine residency didactics and clinical training while also advocating for hospital policy changes, such as widespread reimbursement of PPIUD devices and services in the immediate postpartum setting, ${ }^{13}$ may be strategies for increasing access to this care.

Limitations of our study include generalizability of our findings to all family medicine residents and faculty in the United States. or internationally. In addition, our response rate of $39 \%$ was lower than expected, but was similar to or higher than other electronic surveys of physicians and clinicians on this topic. 6,11 We did not have information on our nonresponders, and thus are unable to evaluate the effects of other potential factors, such as the availability of maternity care training or contraceptive training, on the outcomes of PPIUD training and practice. We also did not have specific information about where faculty respondents may have received prior PPIUD training. Our results show that faculty respondents were younger and more likely to be female than the general family physician population per the American Academy of Family Physicians member census data. ${ }^{14}$

Our study demonstrates a need to improve PPIUD training and placement opportunities for family medicine residents and faculty within WWAMI. It is important for family medicine residency training programs nationwide to incorporate PPIUD training so that residents who continue obstetrical practice may utilize these skills after graduation and so that all residents and faculty, regardless of intention to practice obstetrics, are comfortable with delivering counseling and patient education for PPIUDs.

\section{Tables and Figures}


Table 1: Characteristics of Participants and Participants' Residency Programs

\begin{tabular}{|c|c|c|c|}
\hline & $\begin{array}{c}\text { Residents } \\
n=203 \\
n(\%)\end{array}$ & $\begin{array}{c}\text { Faculty } \\
n=100 \\
n(\%)\end{array}$ & $\begin{array}{c}\text { All Participants } \\
\begin{array}{c}\mathbf{N}=303 \\
\mathbf{N}(\%)\end{array}\end{array}$ \\
\hline \multicolumn{4}{|c|}{ Participant Characteristics } \\
\hline \multicolumn{4}{|c|}{ Gender } \\
\hline Male & $69(34)$ & $51(51)$ & $120(40)$ \\
\hline \multicolumn{4}{|c|}{ Age (Years) } \\
\hline $20-30$ & $123(61)$ & $3(3)$ & $126(42)$ \\
\hline $31-40$ & $76(37)$ & $38(38)$ & $114(38)$ \\
\hline $41-50$ & $4(2)$ & $21(21)$ & $25(8)$ \\
\hline$<5$ & $\mathrm{~N} / \mathrm{A}$ & $21(21)$ & $\mathrm{N} / \mathrm{A}$ \\
\hline $5-10$ & N/A & $23(23)$ & $\mathrm{N} / \mathrm{A}$ \\
\hline$>10$ & $\mathrm{~N} / \mathrm{A}$ & $56(56)$ & $\mathrm{N} / \mathrm{A}$ \\
\hline \multicolumn{4}{|c|}{ Residency Year } \\
\hline $\mathrm{R} 1$ & $68(34)$ & N/A & N/A \\
\hline $\mathrm{R} 2$ & $74(37)$ & N/A & N/A \\
\hline R3 & $61(30)$ & N/A & N/A \\
\hline Provide Inpatient OB Care* & Intend to Provide & Currently Provide & \\
\hline Don't know & $25(12)$ & N/A & N/A \\
\hline
\end{tabular}

(continued on next page) 
Table 1: Continued

\begin{tabular}{|c|c|c|c|}
\hline & $\begin{array}{c}\text { Residents } \\
n=203 \\
n(\%)\end{array}$ & $\begin{array}{c}\text { Faculty } \\
n=100 \\
n(\%)\end{array}$ & $\begin{array}{c}\text { All Participants } \\
\mathbf{N}=303 \\
\mathbf{N}(\%)\end{array}$ \\
\hline \multicolumn{4}{|c|}{ Participant Characteristics } \\
\hline \multicolumn{4}{|c|}{ Program Location by State } \\
\hline WA & $127(63)$ & $62(62)$ & $189(62)$ \\
\hline MT & $27(13)$ & $10(10)$ & $37(12)$ \\
\hline ID & $29(14)$ & $16(16)$ & $45(15)$ \\
\hline \multicolumn{4}{|c|}{ Program Characteristics } \\
\hline \multicolumn{4}{|c|}{ OB Fellowship Available (Classified by Authors**) } \\
\hline \multicolumn{4}{|c|}{ Residency Program Offers Training in PPIUD Placement (Participant Reported) } \\
\hline Yes & $48(24)$ & $30(30)$ & $78(26)$ \\
\hline No & $120(59)$ & $58(58)$ & $178(59)$ \\
\hline Don't know & $35(17)$ & $12(12)$ & $47(16)$ \\
\hline \multicolumn{4}{|c|}{ Hospital Offers PPIUD to Patients (Participant Reported) } \\
\hline Yes & $68(34)$ & $30(30)$ & $98(32)$ \\
\hline No & $113(56)$ & $61(61)$ & $174(57)$ \\
\hline Don't know & $22(11)$ & $9(9)$ & $31(10)$ \\
\hline
\end{tabular}

Abbreviation: PPIUD, postpartum placement of intrauterine devices.

*Based on Accreditation Council for Graduate Medical Education requirements for training in family medicine, $100 \%$ of residents taking the survey were assumed to currently provide inpatient and outpatient OB care. Thus, resident surveys asked whether residents intended to provide inpatient and/or outpatient OB care after residency training, while faculty surveys asked whether they were currently providing inpatient and/or outpatient OB care.

**Not collected as part of survey; added from Family Medicine Residency Network (FMRN) data

Table 2: Training and Experience With PPIUD Placement and Counseling

\begin{tabular}{|c|c|c|c|c|}
\hline Training and Experience & $\begin{array}{l}\text { Residents } \\
n=203\end{array}$ & $\begin{array}{c}\text { Faculty } \\
n=100\end{array}$ & $\begin{array}{l}\text { All Particjpants } \\
\qquad \begin{array}{l}\mathrm{N}=303\end{array}\end{array}$ & $P$ \\
\hline & $\mathrm{n}(\%)$ & $n(\%)$ & $\mathbf{N}(\%)$ & \\
\hline Ever counseled patients about PPIUD & $73(36)$ & $43(43)$ & $116(39)$ & .236 \\
\hline Ever received training for PPIUD placement & $43(21)$ & $36(36)$ & $79(26)$ & .006 \\
\hline Total Number of PPIUD placed ${ }^{*}$ & & & & $<.001$ \\
\hline 0 & $179(88)$ & $72(72)$ & $251(83)$ & \\
\hline $1-5$ & $19(9)$ & $20(20)$ & $39(13)$ & \\
\hline 6 or more & $2(1)$ & $7(7)$ & $9(3)$ & \\
\hline
\end{tabular}

Abbreviation: PPIUD, postpartum placement of intrauterine devices.

* Does not sum to $100 \%$ due to missing responses. 
Table 3: Individual and Program-Specific Characteristics of Family Medicine Residents Who Have Received Immediate PPIUD Training and Those Who Have Ever Placed an Immediate PPIUD

\begin{tabular}{|c|c|c|c|c|}
\hline & $\begin{array}{c}\text { Received PPIUD } \\
\text { Training } \\
\mathrm{N}=43\end{array}$ & $\boldsymbol{P}$ & $\begin{array}{c}\text { Ever Placed } \\
\text { PPIUD } \\
\text { N=21 }\end{array}$ & $\boldsymbol{P}$ \\
\hline & $\mathbf{N}(\%)$ & & $\mathbf{N}(\%)$ & \\
\hline \multicolumn{5}{|c|}{ Hospital Offers PPIUD to Patients (Respondent Reported) } \\
\hline Yes & $25(58)$ & \multirow{2}{*}{$<.001$} & $13(62)$ & \multirow{2}{*}{.009} \\
\hline Don't know & $1(2)$ & & $0(0)$ & \\
\hline \multicolumn{5}{|c|}{ Residency Program Offers Training in PPIUD Placement } \\
\hline Yes & $25(58)$ & \multirow[b]{2}{*}{$<.001$} & $11(52)$ & \multirow[b]{2}{*}{.003} \\
\hline No & $16(37)$ & & $9(43)$ & \\
\hline No & $12(28)$ & \multirow[t]{2}{*}{$<.001$} & $2(10)$ & \multirow[t]{2}{*}{$<.001$} \\
\hline Missing & $2(5)$ & & $2(10)$ & \\
\hline \multicolumn{5}{|c|}{ Ever Placed a PPIUD } \\
\hline Yes & $18(42)$ & \multirow{3}{*}{$<.001$} & $\mathrm{~N} / \mathrm{A}$ & \multirow{3}{*}{$N / A$} \\
\hline No & $23(53)$ & & $N / A$ & \\
\hline Missing & $2(5)$ & & N/A & \\
\hline \multicolumn{5}{|c|}{ Ever rReceived Training for PPIUD Placement } \\
\hline Yes & N/A & $\mathrm{N} / \mathrm{A}$ & $18(86)$ & $<.001$ \\
\hline
\end{tabular}

Abbreviation: PPIUD, postpartum placement of intrauterine devices. 
Table 4: Individual and Program-Specific Characteristics of Family Medicine Faculty Who Have Received Immediate PPIUD Training and Those Who Have Ever Placed an Immediate PPIUD

\begin{tabular}{|c|c|c|c|c|}
\hline & $\begin{array}{c}\text { Received PPIUD } \\
\text { Training } \\
\mathrm{N}=36\end{array}$ & \multirow[t]{2}{*}{$\boldsymbol{P}$} & $\begin{array}{l}\text { Ever Placed } \\
\text { PPIUD } \\
\text { N=27 }\end{array}$ & \multirow[t]{2}{*}{$\boldsymbol{P}$} \\
\hline & $\mathbf{N}(\%)$ & & $\mathbf{N}(\%)$ & \\
\hline \multicolumn{5}{|c|}{ Hospital Offers PPIUD to Patients (Respondent Reported) } \\
\hline Yes & $20(56)$ & \multirow{3}{*}{$<.001$} & $16(59)$ & \multirow{3}{*}{$<.001$} \\
\hline No & $14(39)$ & & $9(33)$ & \\
\hline Don't know & $2(6)$ & & $2(7)$ & \\
\hline \multicolumn{5}{|c|}{ Residency Program Offers Training in PPIUD Placement } \\
\hline Yes & $23(64)$ & \multirow{3}{*}{$<.001$} & $16(59)$ & \multirow{3}{*}{$<.001$} \\
\hline No & $12(33)$ & & $8(30)$ & \\
\hline Don't know or missing & $1(3)$ & & $3(11)$ & \\
\hline \multicolumn{5}{|c|}{ Ever Counseled About PPIUD } \\
\hline Yes & $26(72)$ & \multirow{3}{*}{$<.001$} & $24(89)$ & \multirow{3}{*}{$<.001$} \\
\hline No & $9(25)$ & & $2(7)$ & \\
\hline Missing & $1(3)$ & & $1(4)$ & \\
\hline \multicolumn{5}{|c|}{ Ever Placed a PPIUD } \\
\hline Yes & $21(58)$ & \multirow{3}{*}{$<.001$} & N/A & \multirow{3}{*}{ N/A } \\
\hline No & $14(39)$ & & $\mathrm{N} / \mathrm{A}$ & \\
\hline Missing & $1(3)$ & & N/A & \\
\hline \multicolumn{5}{|c|}{ Ever Received Training for PPIUD Placement } \\
\hline Yes & N/A & \multirow{2}{*}{$\mathrm{N} / \mathrm{A}$} & $21(78)$ & \multirow{2}{*}{$<.001$} \\
\hline No & N/A & & $6(22)$ & \\
\hline \multicolumn{5}{|c|}{ Residency Program Has OB Fellowship } \\
\hline Yes & $4(11)$ & \multirow{2}{*}{.179} & $3(11)$ & \multirow{2}{*}{.275} \\
\hline No & $32(89)$ & & $24(89)$ & \\
\hline
\end{tabular}

Abbreviation: PPIUD, postpartum placement of intrauterine devices.

\section{Acknowledgments}

The authors thank the FMRN for contributing contact information for the survey for this study.

Presentations: This study was previously presented as:

Sheth S, Zhang Y. Experience and Training with Post-placental Intrauterine Device Placement Among Family Medicine Residents and Faculty. Poster Presentation at STFM Annual Spring Conference, Washington DC; May 6, 2018.

\section{Corresponding Author}

Ying Zhang, MD, MPH

University of Washington, Family Medicine Department, 331 NE Thornton PI, Seattle WA 98125.

zhangy07@uw.edu

\section{Author Affiliations}


Ying Zhang, MD, MPH - University of Washington, Family Medicine Department, Seattle, WA

Sonali Sheth, MD - University of Washington, Family Medicine Department, Seattle, WA

Amanda K.H. Weidner, MPH - University of Washington Family Medicine Residency Network, Department of Family Medicine

Patricia Egwuatu, DO - University of Washington, Family Medicine Department, Seattle, WA

Lauren Webb, DO - University of Washington, Family Medicine Department, Seattle, WA

Grace Shih, MD, MPH - University of Washington, Family Medicine Department, Seattle, WA I and University of Washington, Family Medicine Department, Seattle, WA

\section{References}

1. Goldthwaite LM, Shaw KA. Immediate postpartum provision of long-acting reversible contraception. Curr Opin Obstet Gynecol. 2015;27(6):460-464. doi:10.1097/GC0.0000000000000224

2. Kapp N, Curtis KM. Intrauterine device insertion during the postpartum period: a systematic review. Contraception. 2009;80(4):327-336. doi:10.1016/j.contraception.2009.03.024

3. Rodriguez MI, Caughey AB, Edelman A, Darney PD, Foster DG. Cost-benefit analysis of state- and hospital-funded postpartum intrauterine contraception at a university hospital for recent immigrants to the United States. Contraception. 2010;81(4):304-308. doi:10.1016/j.contraception.2009.11.002

4. Washington $\mathrm{Cl}$, Jamshidi R, Thung SF, Nayeri UA, Caughey AB, Werner EF. Timing of postpartum intrauterine device placement: a cost-effectiveness analysis. Fertil Steril. 2015;103(1):131-137. doi:10.1016/j.fertnstert.2014.09.032

5. Zerden ML, Tang JH, Stuart GS, Norton DR, Verbiest SB, Brody S. Barriers to receiving long-acting reversible contraception in the postpartum period. Womens Health Issues. 2015;25(6):616-621. doi:10.1016/j.whi.2015.06.004

6. Holland E, Michelis LD, Sonalkar S, Curry CL. Barriers to immediate post-placental intrauterine devices among attending level educators. Womens Health Issues. 2015;25(4):355-358.

doi:10.1016/j.whi.2015.03.013

7. Moniz M, Chang T, Heisler M, Dalton VK. Immediate postpartum long-acting reversible contraception: the time is now. Contraception. 2017;95(4):335-338. doi:10.1016/j.contraception.2016.11.007

8. Moniz MH, Chang T, Davis MM, Forman J, Landgraf J, Dalton VK. Medicaid administrator experiences with the implementation of immediate postpartum long-acting reversible contraception. Womens Health Issues. 2016;26(3):313-320. doi:10.1016/j.whi.2016.01.005

9. Moniz MH, McEvoy AK, Hofmeister M, Plegue M, Chang T. Family physicians and provision of immediate postpartum contraception: a CERA study. Fam Med. 2017;49(8):600-606. Accessed September 14, 2018.

10. Harris PA, Taylor R, Thielke R, Payne J, Gonzalez N, Conde JG. Research electronic data capture (REDCap)-a metadata-driven methodology and workflow process for providing translational research informatics support. J Biomed Inform. 2009;42(2):377-381. doi:10.1016/j.jbi.2008.08.010

11. Moniz MH, Roosevelt L, Crissman HP, et al. Immediate postpartum contraception: a survey needs assessment of a national sample of midwives. J Midwifery Womens Health. 2017;62(5):538-544. doi:10.1111/jmwh.12653

12. Ogburn JA, Espey E, Stonehocker J. Barriers to intrauterine device insertion in postpartum women. Contraception. 2005;72(6):426-429. doi:10.1016/j.contraception.2005.05.016

13. Moniz MH, Dalton VK, Davis MM, et al. Characterization of Medicaid policy for immediate postpartum contraception. Contraception. 2015;92(6):523-531. doi:10.1016/j.contraception.2015.09.014

14. Physician Specialty Data Report. Association of American Medical Colleges. 2017. Accessed October 30, 2019. https://www.aamc.org/data-reports/workforce/interactive-data/active-physicians-age-and-

specialty-2017 
Copyright $(\subset 2021$ by the Society of Teachers of Family Medicine 